\title{
Unusually aggressive primary cloacogenic carcinoma of the vulva: A case report and literature review
}

\author{
Rajni Chibbar ${ }^{1}$, Kimberly A. Wood ${ }^{2}$, Christopher K. Giede ${ }^{3}$, Anita Agrawal $^{4 *}$ \\ ${ }^{1}$ Department of Pathology, University of Saskatchewan, Saskatoon, Canada \\ ${ }^{2}$ College of Medicine, University of Saskatchewan, Saskatoon, Canada \\ ${ }^{3}$ Department of Obstetrics and Gynecology, Royal University Hospital, Saskatoon, Canada \\ ${ }^{4}$ Department of Obstetrics and Gynecology, University of Saskatchewan, Saskatoon, Canada; \\ *Corresponding Author: anita.agrawal@usask.ca
}

Received 11 November 2012; revised 8 December 2012; accepted 12 January 2013

Copyright (C) 2013 Rajni Chibbar et al. This is an open access article distributed under the Creative Commons Attribution License, which permits unrestricted use, distribution, and reproduction in any medium, provided the original work is properly cited.

\begin{abstract}
Vulvar cancer is an uncommon tumor and represents $3 \%-5 \%$ of all female genital tract malignancies. The overall incidence is $1.5 / 100,000$ women. Histopathologically the vast majority (90\%) are squamous cell carcinomas. Primary cloacogenic carcinoma of the vulva is extremely rare with less than 20 cases reported in English literature [1]. These tumors are thought to arise from embryonic or ectopic rests of cloacogenic tissue. The majority of these reported cases is relatively indolent cancer, only one case of cloacogenic carcinoma of the vulva reported metastatic spread to the inguinal lymph nodes and none that describe distant metastases. Here we present an aggressive and diagnostically challenging case of cloacogenic carcinoma of the vulva and a review of current literature to date.
\end{abstract}

Keywords: Cloacogenic Vulvar Cancer; Metastasis

\section{INTRODUCTION}

Primary cancer of the vulva is rare accounting for only $3 \%-5 \%$ of all lower female genital tract cancers. Primary cloacogenic carcinoma of the vulva is extremely rare with less than 20 cases reported in English literature [1]. Only one case reported metastatic spread to inguinal lymph nodes and none that describe distant metastases. These tumors are thought to arise from embryonic or ectopic rests of cloacogenic tissue. Here we present a case of primary cloacogenic carcinoma of the vulva which metastasized to the lungs and bilaterally to inguinal and pelvic lymph nodes at initial presentation.

\section{CASE REPORT}

A 49-year-old nulligravida postmenopausal woman presented in March of 2010, with multiple small vulvar lesions an accompanying three weeks history of pain, pressure on vulva, bleeding, pruritus and swelling. Physical examination revealed severe swelling and multiple erythematous tender small nodules less than $1 \mathrm{~cm}$ in size on the vulva and lower vaginal canal and palpable lymph nodes in the right groin (Figure 1(A)).

Magnetic resonance imaging (MRI) of the pelvis showed a $3.8 \times 3.4 \mathrm{~cm}$ lobular heterogeneously enhancing mass located in the lower region of the vaginal canal and vulva. CT scan reported spread to the lung and inguinal and pelvic lymph nodes with bilateral heterogeneously enhancing multi-lobulated masses in the groin measuring $6.1 \times 5.9 \mathrm{~cm}$ in the right, and $4.8 \times 5.0 \mathrm{~cm}$ in the left. Punch biopsies of the left vulva reported moderately differentiated adenocarcinoma with a depth of invasion of $3.74 \mathrm{~mm}$ (Figure 1(B)). Lymphovascular space invasion was noted. A non-neoplastic, slightly dilated gland lined by non-neoplastic columnar epithelium and goblet cells was present within the overlying squamous epithelium. On immunohistochemistry neoplastic cells were highlighted with cytokeratin (CK) 20 (Figure 1(C)), CDX-2 (Figure 1(D)), carcinoembryonic antigen (CEA) and p53. Mucicarmine stain was positive. Neoplastic cells were negative with CK7, estrogen receptor (ER), progesterone receptor (PR), Wilm's tumor-1 (WT-1), p16, vimentin and S-100 antibodies. Based on histology and immune profiling a metastatic from the gastrointestinal tract was suggested. Clinical evaluation of the gastrointestinal tract 

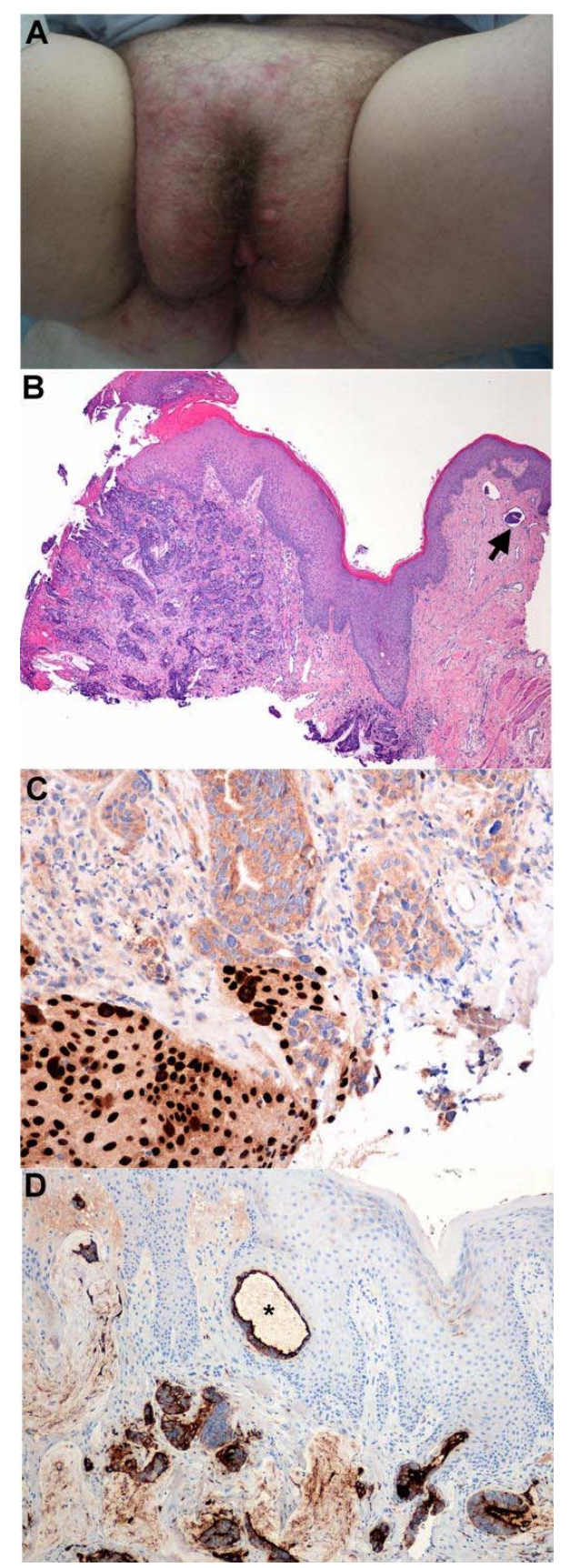

Figure 1. (A) Gross appearance of lesions on vulva; (B) Low power ( $\mathrm{H} \& \mathrm{E} \times 4)$ of lesion present on excisional biopsy of vulva and lymphovascular invasion (arrow); (C) CDX-2 nuclear staining of neoplastic cells; (D) CK-7 cytoplasmic staining for neoplastic cells and nonneoplastic gland $(*)$.

by colonscopy and computer topography (CT) showed no pathology.

The vulvar cancer was treated urgently with radical concurrent chemo-radiation over 43 days. After completion she underwent bilateral inguinal lymph node debulking. Residual vulvar tumor, persistent enlarged pel- vic lymph nodes, and lung lesions were noted in a subsequent CT follow up and she was treated with carboplatin-paclitaxel as a second line chemotherapy for 6 cycles. After that bilateral external iliac lymph node debulking was carried out for persistent pelvic lymph nodes and histopathology reported viable tumor cells. In all three histopathology specimens from various procedures, neoplastic cells had a striking resemblance to colonic adenocarcinoma and a diagnosis of cloacogenic carcinoma was made. The patient was treated with FOLFIRI chemotherapy for three cycles with no response and was then advised for no further chemotherapy. She was referred to palliative services for pain control and she died after 27 months of initial diagnosis.

\section{DISCUSSION}

Only a few cases have reported adenocarcinoma arising from cloacal remnants. The average age of women reported with cloacogenic tumors of the vulva or lower genital tract was 51 years old and ranged from 35 to 67 years of age. Majority of the cases (Table 1) described solitary tumors that ranged in size from 1.0 to $2.0 \mathrm{~cm}$ largest diameter, presenting on the external urethral meatus [2], labia majora [3], posterior vulva [4], posterior fourchette [4-6], Bartholin's gland [1], vagina [7] and cervix [7]. One case describes multiple tumors ranging in size from 0.1 to $1.4 \mathrm{~cm}$ on posterior to the fourchette [8].

Cell origin of these tumours is still unclear but it has been proposed that they arise from remnant cells of the cloacal membrane [2,6-8]. During the fourth to sixth week of gestation the urorectal septum partitions the cloaca into the primitive urogenital sinus ventrally and the anal canal dorsally [9]. Distally, the urorectal septum comes into contact with the anal membrane in this area and forms the perineum. The anal pit is formed from proliferating mesenchymal cells around the anal membrane. The anal canal becomes patent around the seventh to eighth week of gestation when the anal membrane ruptures creating a zone of separation that is demonstrated by an irregular folding of the adult mucosa, the pectinate line.

The primitive urogenital sinus consists of three areas. The superior portion expands to derive the bladder, the narrow middle portion forms the pelvic urethra and the inferior portion expands to form the definitive urogenital sinus [9]. The definitive urogenital sinus is enclosed by the urogenital membrane and goes on to form the endoderm-lined urethral groove, and later on the vestibule. Externally, a pair of swellings adjacent to the urogenital membrane forms the cloacal folds (the urogenital folds) and the labioscrotal folds, which go on to form the labia minoria and labia majoria, respectively. In the seventh week of gestation the urogenital membrane ruptures cre- 
Table 1. Summary of clinical presentations and management of 12 patients.

\begin{tabular}{|c|c|c|c|c|c|c|}
\hline Author & Age & Lesion type & $\begin{array}{l}\text { Lymph node } \\
\text { metastasis }\end{array}$ & $\begin{array}{c}\text { Distant } \\
\text { metastasis }\end{array}$ & Treatment & Prognosis (months) \\
\hline Lui et al., 2002, [1] & 49 & Left labia minora & No & No & WLE/UL IFLND & AWH at 24 months \\
\hline Tiltman et al., 1978, [2] & 50 & External urinary meatus & Yes & No & $\begin{array}{l}\text { Modified radical } \\
\text { Vulvectomy and B/L IFLND }\end{array}$ & NA \\
\hline Dube et al., 2004, [3] & 58 & Right labia majora & No & No & $\begin{array}{l}\text { Right hemivulvectomy and } \\
\text { UL IFLND }\end{array}$ & AWH at 16 months \\
\hline Kennedy et al., 1993, [4] & $\begin{array}{l}54 \\
63\end{array}$ & $\begin{array}{l}\text { Left Posterior vulva } \\
\text { Posterior fourchette }\end{array}$ & No & $\begin{array}{l}\text { No } \\
\text { No }\end{array}$ & $\begin{array}{l}\text { Radical vulvectomy and } \mathrm{B} / \mathrm{L} \\
\text { IFLND } \\
\text { WLE }\end{array}$ & $\begin{array}{l}10 \text { years (died of } \\
\text { urosepsis) } \\
\text { AWH at } 4 \text { years }\end{array}$ \\
\hline Ghamande et al., 1995, [5] & 67 & Posterior fourchette & No & No & $\begin{array}{l}\text { Radical vulvectomy and } \\
\text { B/L IFLND }\end{array}$ & NA \\
\hline Willen et al., 1998, [6] & 57 & Left posterior vestibulum & No & No & WLE & AWH at 26 months \\
\hline Fox et al., 1988, [7] & $35,43,59$ & Vaginal vault & & & & \\
\hline Zaidi et al., 2001, [8] & 43 & Posterior fourchette & No & No & Partial posterior vulvectomy & AWH at 18 months \\
\hline Lee et al., 1990, [11] & 27 & Multifocal & No & & & \\
\hline
\end{tabular}

ating a patent urogenital sinus. Therefore in the vestibule and the labia minora, remnants of cloacal membrane could persist and give rise to cloacogenic carcinoma of the vulva. Remnants of cloacal membrane persist proximal to the pectinate line from where transitional cell cloacogenic carcinoma can arise [10].

Treatment for the majority of the cases presented was radical vulvectomy and bilateral local lymph node excision $[2,4,5,8]$, with the more recent cases pursuing local excision with bilateral local lymph node excision $[1,3,6]$. In the majority of the cases the tumor did not metastasized and was referred to as indolent in nature and excision of the lesion(s) appeared to be curative[1,3-5,7,8] however Willen et al. [6] reported recurrence of the tumor one year later, and performed a wider resection of the tumor. Our case, the tumor was aggressive in nature with metastatic spread to inguinal and pelvic lymph nodes and the lung. Complete excision of the tumor was not possible in this case due the extent of tumor involvement and metastasis and therefore was initially treated with concurrent chemo-radiation therapy. Patient had partial response to the treatment with some tumor regression and pain relief, but the neoplastic cells remained viable in the vulvar lesions after therapy was completed. Patient then received second line carboplatinpaclitaxel chemotherapy for persistent metastatic disease after initial treatment. The other reported case of metastatic spread to local lymph node, excision only was required for treatment and patient was reported to be doing well one year after [2].

The majority of the cases reported a single tumor arising in direct continuity with the surface epithelium [1-6]. The tumor in our case was multifocal and it was difficult to assess if the tumors arose in continuity with or beneath the surface epithelium as only two punch and one exisional biopsy of the vulva where evaluated, where other cases examine tissue from complete or partial vulvectomy. Fox et al. [7] describe a tumor originating in the vagina vault that had similar microscopic appearance as the tumor described here, with the lesion presenting beneath an ulcerated overlying epithelium. Zaidi and Conner [8] reported a case of multiple surface nodules in direct continuity with the surface epithelium that was focally ulcerated.

Metastatic adenocarcinoma of the vulva was considered initially as the lesions had many characteristics of a tumor derived from enteric origin however this was excluded as there was no evidence of a previous or concurrent primary tumor of similar histological appearance. Also metastatic spread to the pelvic and inguinal lymph nodes did not consist with a primary colonic adenocarcinoma but was in keeping with a primary carcinoma of the vulva. Therefore, primary cloacogenic carcinoma was determined in this case due to morphological appearance and immune-histochemistry staining of the neoplastic cells along with pattern of metastatic spread. Neoplastic cells had a striking resemblance to colonic adenocarcinoma with the presence of one non-neoplastic gland. The presence of non-neoplastic glands was remarked by others $[2,3,6,8]$.

\section{CONCLUSION}

Primary cloacogenic carcinoma of the vulva is very rare but it is important for pathologists and clinicians to be aware of. Any lesion seen on the vulva and perineum should be biopsied at its earliest and have a pathology review for diagnosis confirmation. Detailed clinical workup and careful histopathological examination using histopathology and immune-histochemistry is necessary to make the early diagnosis and less radical management. It is considered to be of indolent nature but in the case of 
our case it acted aggressively despite radical treatment. Therefore, early recognition and wide local excision of the tumor(s) prior to metastatic spread is important for favourable prognosis and decreased reoccurrence.

\section{REFERENCES}

[1] Lui, S.H., Ho, C.M., Huang, S.H., et al. (2003) Cloacogenic adenocarcinoma of the vulva presenting as recurrent Bartholin's gland infection. Journal of the Formosan Medical Association, 102, 49-51.

[2] Titlman, A.J. and Knutzen, V.K. (1978) Primary adenocarcinoma of the vulva originating in misplaced cloacal tissue. Obstetrics \& Gynecology, 51, 30s-33s.

[3] Dube, V., Veilleux, C., Plante, M., et al. (2004) Primary villoglandular adenocarcinoma of cloacogenic origin of the vulva. Human Pathology, 35, 377-379. doi:10.1016/j.humpath.2003.05.002

[4] Kennedy, J.C. and Majmudar, B. (1993) Primary adenocarcinoma of the vulva, possibly cloacogenic: A report of two cases. Journal of Reproductive Medicine, 38, 113116.

[5] Ghamande, S.A., Kasznica, J., Griffiths, C.T., et al. (1995) Mucinous adenocarcinomas of vulva. Gynecologic Oncology, 57, 117-120. doi:10.1006/gyno.1995.1108
[6] Willen, R., Békássy, Z., Carlén, B., et al. (1999) Cloacogenic adenocarcinoma of the vulva. Gynecologic Oncology, 74, 298-301. doi:10.1006/gyno.1999.5433

[7] Fox, H., Wells, M., Harris, M., et al. (1988) Enteric tumours of the lower female genital tract: A report of three cases. Histopathology, 12, 167-176. doi:10.1111/j.1365-2559.1988.tb01927.x

[8] Zaida, S.N.H. and Conner, M.G. (2001) Primary vulvar adenocarcinoma of cloacogenic origin. Southern Medical Journal, 94, 744-746. doi:10.1097/00007611-200107000-00025

[9] Larson, W.J. (1997) Development of the urogenital system. In: Human Embryology, 2nd Edition, Churchill Livingstone Inc., New York, 261-310.

[10] Sink, J.D., Kramer, S.A., Copeland, D.D., et al. (1978) Cloacogenic carcinoma. Annals of Surgery, 188, 53-59. doi:10.1097/00000658-197807000-00009

[11] Lee, K.C., Su, W.P. and Muller, S.A., (1990) Multicentric cloacogenic carcinoma: Report of a case with anogenital pruritus at presentation. Journal of American Academy of Dermatology, 23, 1005-1008. doi:10.1016/0190-9622(90)70323-A 